\title{
Enhanced of Electrical Properties and Shielding Efficiency of Hybrid Composite with Temperature
}

\author{
Tahar Merizgui $^{1,2^{*}}$, Abdechafik Hadjadj ${ }^{2}$, Mecheri Kious ${ }^{1}$, Bachir Gaoui ${ }^{1}$ \\ ${ }^{1}$ Laboratoire des Semi-conducteur et Matériaux Fonctionnel, BP 37G, Université Amar Telidji de Laghouat, Laghouat 03000, \\ Algeria \\ ${ }^{2}$ Laboratoire d'analyse, de commande des systèmes d'Energies et Réseaux électrique, Université Amar Telidji de Laghouat, \\ Laghouat 03000, Algeria
}

Corresponding Author Email: t.merizgui@lagh-univ.dz

https://doi.org/10.18280/rcma.290307

Received: 8 March 2019

Accepted: 26 May 2019

\section{Keywords:} PMC, shielding effectiveness,
temperature, conductivity, hybrid composite

\begin{abstract}
In this paper, we present a comparison study between theoretical and experimental results to improve the performance of materials such as electrical proprieties (permeability, permittivity, and conductivity) and shielding efficiency at high temperature by using a different designation of hybrid composite. The main aim of this research study is to prepare a high stable microwave shielding hybrid epoxy composite with a modified surface MWCNTs and Iron (III) oxide nano particles addition in epoxy resin matrix/Kenaf fibre. The morphology of the obtained shields was investigated by scanning electron microscopy. Thus, additions of MWCNTs and iron (III) oxide particles increase the shielding effectiveness with a modified surface on these reinforcements by increasing the electrical behavior against the external radiation at high temperature of epoxy matrix with incremental of temperature.
\end{abstract}

\section{INTRODUCTION}

Nowadays, the electromagnetic shielding materials is a very important field and became a main stream of research all over the world in many application such as health care, electronics and industrial to protect them from the external radiations [12]. It radically solves the problem by removing the electromagnetic interference EMI. Composite absorbers material is one of the major challenges in many applications of shielding materials which are often microscopic due to its light weight [3-4]. The absorption mechanism (A), reflection mechanism (R), and electromagnetic interference EMI shielding effectiveness SE of the epoxy matrix-kenaf fibre(MWCNT/ $\mathrm{Fe}_{2} \mathrm{O}_{3}$ ) particle-reinforced conducting composite sheets is evaluated in this paper by using $\varepsilon, \mu$, and $\sigma$ for near field region at several temperature [5-6].

The morphology of the obtained our prepared shields was investigated by scanning electron microscopy (SEM) images. The kenaf fibre increase in the mechanical properties such as the flexural, tensile. Thus, magnetic particles prevent the magnetic component and conductive particles prevent the electric component of the incoming waves. The magnetic permeability that influences on the EMI SE by absorption coefficient is a very important parameter to stop and absorb the external radiations with less outside reflection from the boundary of materials. Several of authors concluded that additions of compound particles of $\mathrm{Cu}$-Magnetite blend in to epoxy resin improved the microwave attenuation behaviour of epoxy shield up to $38 \mathrm{~dB}$ [7]. They have produced the compound form of particles by ball milling the particles up to 8 hours. Some authors concluded that the addition of surface treated MWCNT in to epoxy resin matrix increased microwave attenuation behaviour up to $84 \mathrm{~dB}$. The dispersion morphology of particle may enforce maximum impact on the attenuation behaviour. The morphology could be analysed by using a scanning electron microscopy [8-9]. The dispersion of MWCNT could be estimated via a high-resolution transmission electron microscope.

In the near field the distance between the source and conducting sheet is very little, and the wave impedance is not similar to the impedance $377 \Omega$ for free space and it is the perform of source properties defined as the ratio of electric field and magnetic field. In the case of high impedance, electric field will be dominated; on the contrary, magnetic field will be dominated in the case of low impedance. Thus, the SE in electric field does not similar to SE in magnetic field and vary as a function of distance between the conducting shield and the electromagnetic source noises. Which is quite different from its behavior in far field, when the wave impedance is constant and it is equal to $377 \Omega$ of the medium. The distinctive impedance of a media is expressed by the ratio of the electric field $\mathrm{E}$ to the magnetic field $\mathrm{H}$. It is given by the equation [10-12]:

$$
Z=\sqrt{\frac{j \cdot \omega \cdot \mu}{\sigma+j \cdot \omega \cdot \varepsilon}}
$$

where, $w$ represents the expressed the frequency, $\mu$ the permeability, $\sigma$ the conductivity and $\varepsilon$ the permittivity. For an insulating media the conductivity is very low, therefore, the free space impedance is:

$$
Z_{\mathrm{o}}=\sqrt{\frac{\mu_{\mathrm{o}}}{\varepsilon_{\mathrm{o}}}}=377 \Omega
$$

For a conducting media, the impedance wave is express as: 


$$
Z=\sqrt{\frac{j \cdot \omega \cdot \mu}{\sigma}}
$$

\section{EXPERIMENTAL PROCEDURE}

\subsection{Materials (as received)}

The epoxy matrix used here was Araldite LY556, $190 \mathrm{~g} / \mathrm{mol}$ and density of $1.2 \mathrm{~g} / \mathrm{cm}^{3}$. The MWCNTs of diameter $30 \mathrm{~nm}$ and length $110 \mathrm{~nm}$ and Iron(III) oxide of $<50 \mathrm{~nm}$ were procured from Sigma Aldrich, USA. Kenaf fibre of Continuous woven mat $\left(90^{\circ} / 0^{\circ}\right)$ and density $2.8 \mathrm{~g} / \mathrm{cm}^{3}$ was used as fibre reinforcement. The surface modifier APTMS was purchased from Sigma Aldrich, USA. All the chemicals were used in as-received condition without any post treatment processes. Table 1 shows the composite composition and designation used in this our investigation work [5]:

\subsection{Surface modification (surface-modified)}

The kenaf woven fibre mat, MWCNTs and iron (III) oxide nano particles were surface-modified by immersion aqueous solution method to improve adhesion of fibre and dispersion of particle in resin matrix. In this process both the fibre and particle reinforcements are subjected for complete immersion in aqueous solution of $95 \%$ concentration by weight. Generally, 5 weight percentage of water was mixed with ethanol to produce diluted aqueous solution for effective silane functionalization. To adjust $\mathrm{pH}$ value between 4.5 to 5.5 acetic acid of required amount was mixed gently and mixed thoroughly.

Table 1. Designation and composition of composites in this present study

\begin{tabular}{cccccc}
\hline S.No & Desig-nation & Epoxy vol.\% & Kenaf fibre vol.\% & MWCNT vol.\% & Iron (III) oxide vol.\% \\
\hline 1 & A & 100 & 0 & 0 & 0 \\
2 & B & 69 & 30 & 0.5 & 0.5 \\
3 & C & 68.5 & 30 & 0.5 & 1.0 \\
4 & D & 68.5 & 30 & 1.0 & 0.5 \\
5 & E & 68 & 30 & 1.0 & 1.0 \\
\hline
\end{tabular}

\subsection{Electrical conductivity improvement}

It is well observed that the pure epoxy has the conductivity of $1.85 \mathrm{E}^{-7}$ at room temperature and it gradually increases with the temperature. This increase of conductivity with the temperature is the cause of higher particle network and decrease in resistivity. When temperate increases above the glass transition temperature the rigid epoxy becomes flexible, at the same time the dispersed iron oxide particle may form a particle network and start conduct the charges. It is further noted that the surface-modified iron oxide and MWCNTs gives a higher conductivity than as-received one. This improvement is the reason of good dispersion of particle at high denser matrix medium as shown in Table 2, 3, 4, and 5 respectively.

The increase of conductivity refers to the increasing of temperature and frequency. At this stage the epoxy becomes softer since the temperature is more than its glass transition temperature. Thereby, the particles are easily forming a network rather than hard rigid medium. This increase of frequency improves more vibration on particle, which increase the chances of particle network formation.

Table 2. Electrical conductivity of composites (G) at $100 \mathrm{~Hz}$

\begin{tabular}{|c|c|c|c|c|c|c|}
\hline \multirow[b]{2}{*}{ S.No } & \multicolumn{2}{|c|}{ Room temperature } & \multicolumn{2}{|c|}{$100^{\circ} \mathrm{C}$} & \multicolumn{2}{|c|}{$200^{\circ} \mathrm{C}$} \\
\hline & As-received & $\begin{array}{l}\text { Surface- } \\
\text { modified }\end{array}$ & As-received & $\begin{array}{l}\text { Surface- } \\
\text { modified }\end{array}$ & As-received & $\begin{array}{l}\text { Surface- } \\
\text { modified }\end{array}$ \\
\hline A & \multicolumn{2}{|c|}{$1.85 \mathrm{E}^{-7}$} & \multicolumn{2}{|c|}{$3.73 \mathrm{E}^{-7}$} & \multicolumn{2}{|c|}{$1.01 \mathrm{E}^{-6}$} \\
\hline B & $2.82 \mathrm{E}^{-7}$ & $3.41 \mathrm{E}^{-7}$ & $4.31 \mathrm{E}^{-7}$ & $4.78 \mathrm{E}^{-7}$ & $1.66 \mathrm{E}^{-6}$ & $2.24 \mathrm{E}^{-6}$ \\
\hline $\mathrm{C}$ & $4.42 \mathrm{E}^{-7}$ & $5.92 \mathrm{E}^{-7}$ & $4.78 \mathrm{E}^{-7}$ & $5.99 \mathrm{E}^{-7}$ & $2.80 \mathrm{E}^{-6}$ & $7.84 \mathrm{E}^{-6}$ \\
\hline $\mathrm{D}$ & $3.05 \mathrm{E}^{-7}$ & $3.89 \mathrm{E}^{-7}$ & $5.02 \mathrm{E}^{-7}$ & $6.30 \mathrm{E}^{-7}$ & $2.65 \mathrm{E}^{-6}$ & $7.40 \mathrm{E}^{-7}$ \\
\hline E & $5.23 \mathrm{E}^{-7}$ & $6.91 \mathrm{E}^{-7}$ & $6.42 \mathrm{E}^{-7}$ & $7.45 \mathrm{E}^{-7}$ & $3.64 \mathrm{E}^{-6}$ & $8.76 \mathrm{E}^{-6}$ \\
\hline
\end{tabular}

Table 3. Electrical conductivity of iron oxide/MWCNTs epoxy composites vs. frequency at RT

\begin{tabular}{|c|c|c|c|c|c|c|c|c|c|c|c|c|}
\hline \multirow{2}{*}{ Composites } & \multicolumn{2}{|c|}{$50 \mathrm{~Hz}$} & \multicolumn{2}{|c|}{$100 \mathrm{~Hz}$} & \multicolumn{2}{|c|}{$1 \mathrm{KHz}$} & \multicolumn{2}{|c|}{$50 \mathrm{KHz}$} & \multicolumn{2}{|c|}{$50 \mathrm{MHz}$} & \multicolumn{2}{|c|}{$50 \mathrm{GHz}$} \\
\hline & UM & SM & UM & SM & UM & SM & UM & SM & UM & SM & UM & SM \\
\hline A & \multicolumn{2}{|c|}{$1.85 \mathrm{E}^{-7}$} & \multicolumn{2}{|c|}{$2.644 \mathrm{E}^{-7}$} & \multicolumn{2}{|c|}{$4.23 \mathrm{E}^{-7}$} & \multicolumn{2}{|c|}{$5.93 \mathrm{E}^{-7}$} & \multicolumn{2}{|c|}{$7.43 \mathrm{E}^{-7}$} & \multicolumn{2}{|c|}{$2.55 \mathrm{E}^{-6}$} \\
\hline B & $2.31 \mathrm{E}^{-7}$ & $2.95 \mathrm{E}^{-7}$ & $2.82 \mathrm{E}^{-7}$ & $3.41 \mathrm{E}^{-7}$ & $4.53 \mathrm{E}^{-7}$ & $5.65 \mathrm{E}^{-7}$ & $6.74 \mathrm{E}^{-7}$ & $7.97 \mathrm{E}^{-7}$ & $7.67 \mathrm{E}^{-7}$ & $8.42 \mathrm{E}^{-7}$ & $2.86 \mathrm{E}^{-6}$ & $3.12 \mathrm{E}^{-6}$ \\
\hline $\mathrm{C}$ & $2.90 \mathrm{E}^{-7}$ & $3.51 \mathrm{E}^{-7}$ & $4.42 \mathrm{E}^{-7}$ & $5.92 \mathrm{E}^{-7}$ & $6.11 \mathrm{E}^{-7}$ & $7.62 \mathrm{E}^{-7}$ & $8.88 \mathrm{E}^{-7}$ & $9.13 \mathrm{E}^{-7}$ & $9.47 \mathrm{E}^{-7}$ & $9.90 \mathrm{E}^{-7}$ & $3.06 \mathrm{E}^{-6}$ & $4.63 \mathrm{E}^{-6}$ \\
\hline D & $2.41 \mathrm{E}^{-7}$ & $2.92 \mathrm{E}^{-7}$ & $3.05 \mathrm{E}^{-7}$ & $3.89 \mathrm{E}^{-7}$ & $4.85 \mathrm{E}^{-7}$ & $6.01 \mathrm{E}^{-7}$ & $6.86 \mathrm{E}^{-7}$ & $8.52 \mathrm{E}^{-7}$ & $8.32 \mathrm{E}^{-7}$ & $9.25 \mathrm{E}^{-7}$ & $3.61 \mathrm{E}^{-6}$ & $3.99 \mathrm{E}^{-6}$ \\
\hline E & $3.14 \mathrm{E}^{-7}$ & $4.76 \mathrm{E}^{-7}$ & $5.23 \mathrm{E}^{-7}$ & $6.91 \mathrm{E}^{-7}$ & $7.56 \mathrm{E}^{-7}$ & $8.61 \mathrm{E}^{-7}$ & $9.72 \mathrm{E}^{-7}$ & $9.86 \mathrm{E}^{-7}$ & $9.90 \mathrm{E}^{-7}$ & $1.48 \mathrm{E}^{-6}$ & $3.45 \mathrm{E}^{-6}$ & $5.17 \mathrm{E}^{-6}$ \\
\hline
\end{tabular}

Note: UM- unmodified; SM- Surface modified; same as below. 
Table 4. Electrical conductivity of iron oxide/MWCNTs epoxy composites vs. frequency at $100{ }^{\circ} \mathrm{C}$

\begin{tabular}{|c|c|c|c|c|c|c|c|c|c|c|c|c|}
\hline \multirow{2}{*}{ Composites } & \multicolumn{2}{|c|}{$50 \mathrm{~Hz}$} & \multicolumn{2}{|c|}{$100 \mathrm{~Hz}$} & \multicolumn{2}{|c|}{$1 \mathrm{KHz}$} & \multicolumn{2}{|c|}{$50 \mathrm{KHz}$} & \multicolumn{2}{|c|}{$50 \mathrm{MHz}$} & \multicolumn{2}{|c|}{$50 \mathrm{GHz}$} \\
\hline & UM & SM & UM & SM & UM & SM & UM & SM & UM & SM & UM & SM \\
\hline $\mathrm{A}$ & \multicolumn{2}{|c|}{$2.55 \mathrm{E}^{-7}$} & \multicolumn{2}{|c|}{$3.73 \mathrm{E}^{-7}$} & \multicolumn{2}{|c|}{$4.64 \mathrm{E}^{-7}$} & \multicolumn{2}{|c|}{$6.73 \mathrm{E}^{-7}$} & \multicolumn{2}{|c|}{$7.98 \mathrm{E}^{-7}$} & \multicolumn{2}{|c|}{$3.11 \mathrm{E}^{-6}$} \\
\hline B & $2.87 \mathrm{E}^{-7}$ & $3.27 \mathrm{E}^{-7}$ & $4.31 \mathrm{E}^{-7}$ & $4.78 \mathrm{E}^{-7}$ & $5.87 \mathrm{E}^{-7}$ & $6.45 \mathrm{E}^{-7}$ & $7.25 \mathrm{E}^{-7}$ & $8.41 \mathrm{E}^{-7}$ & $8.88 \mathrm{E}^{-7}$ & $9.42 \mathrm{E}^{-7}$ & $3.76 \mathrm{E}^{-6}$ & $4.32 \mathrm{E}^{-6}$ \\
\hline $\mathrm{C}$ & $3.10 \mathrm{E}^{-7}$ & $3.76 \mathrm{E}^{-7}$ & $4.78 \mathrm{E}^{-7}$ & $5.99 \mathrm{E}^{-7}$ & $6.22 \mathrm{E}^{-7}$ & $6.89 \mathrm{E}^{-7}$ & $7.89 \mathrm{E}^{-7}$ & $9.33 \mathrm{E}^{-7}$ & $9.32 \mathrm{E}^{-7}$ & $9.94 \mathrm{E}^{-7}$ & $4.11 \mathrm{E}^{-6}$ & $4.87 \mathrm{E}^{-6}$ \\
\hline D & $2.76 \mathrm{E}^{-7}$ & $3.12 \mathrm{E}^{-7}$ & $5.02 \mathrm{E}^{-7}$ & $6.30 \mathrm{E}^{-7}$ & $8.87 \mathrm{E}^{-7}$ & $6.63 \mathrm{E}^{-7}$ & $7.15 \mathrm{E}^{-7}$ & $8.92 \mathrm{E}^{-7}$ & $9.00 \mathrm{E}^{-7}$ & $9.65 \mathrm{E}^{-7}$ & $3.91 \mathrm{E}^{-6}$ & $4.28 \mathrm{E}^{-6}$ \\
\hline $\mathrm{E}$ & $3.80 \mathrm{E}^{-7}$ & $4.90 \mathrm{E}^{-7}$ & $6.42 \mathrm{E}^{-7}$ & $7.45 \mathrm{E}^{-7}$ & $8.02 \mathrm{E}^{-7}$ & $8.98 \mathrm{E}^{-7}$ & $9.99 \mathrm{E}^{-7}$ & $1.43 \mathrm{E}^{-6}$ & $1.69 \mathrm{E}^{-6}$ & $2.69 \mathrm{E}^{-6}$ & $3.75 \mathrm{E}^{-6}$ & $5.92 \mathrm{E}^{-6}$ \\
\hline
\end{tabular}

Table 5. Electrical conductivity of iron oxide/MWCNTs epoxy composites vs. frequency at $200{ }^{\circ} \mathrm{C}$

\begin{tabular}{|c|c|c|c|c|c|c|c|c|c|c|c|c|}
\hline \multirow{2}{*}{ Composites } & \multicolumn{2}{|c|}{$50 \mathrm{~Hz}$} & \multicolumn{2}{|c|}{$100 \mathrm{~Hz}$} & \multicolumn{2}{|c|}{$1 \mathrm{KHz}$} & \multicolumn{2}{|c|}{$50 \mathrm{KHz}$} & \multicolumn{2}{|c|}{$50 \mathrm{MHz}$} & \multicolumn{2}{|c|}{$50 \mathrm{GHz}$} \\
\hline & UM & SM & UM & SM & UM & SM & UM & SM & UM & SM & UM & SM \\
\hline A & \multicolumn{2}{|c|}{$8.63 \mathrm{E}^{-7}$} & \multicolumn{2}{|c|}{$1.01 \mathrm{E}^{-6}$} & \multicolumn{2}{|c|}{$2.65 \mathrm{E}^{-6}$} & \multicolumn{2}{|c|}{$4.12 \mathrm{E}^{-6}$} & \multicolumn{2}{|c|}{$6.31 \mathrm{E}^{-6}$} & \multicolumn{2}{|c|}{$8.68 \mathrm{E}^{-6}$} \\
\hline B & $8.88 \mathrm{E}^{-7}$ & $9.20 \mathrm{E}^{-7}$ & $1.66 \mathrm{E}^{-6}$ & $2.24 \mathrm{E}^{-6}$ & $3.28 \mathrm{E}^{-6}$ & $4.67 \mathrm{E}^{-6}$ & $4.24 \mathrm{E}^{-6}$ & $5.04 \mathrm{E}^{-6}$ & $6.97 \mathrm{E}^{-6}$ & $7.42 \mathrm{E}^{-6}$ & $8.90 \mathrm{E}^{-6}$ & $9.51 \mathrm{E}^{-6}$ \\
\hline $\mathrm{C}$ & & & $2.80 \mathrm{E}^{-6}$ & $.84 \mathrm{E}^{-6}$ & $69 \mathrm{E}^{-6}$ & 5.9 & $5.37 \mathrm{E}^{-6}$ & 6.6 & $7.21 \mathrm{E}^{-6}$ & & $9.47 \mathrm{E}^{-6}$ & $9 \mathrm{E}^{-6}$ \\
\hline $\mathrm{D}$ & $8 \mathrm{E}^{-7}$ & 9.21 & $2.65 \mathrm{E}^{-6}$ & $7.40 \mathrm{E}^{-6}$ & $3.16 \mathrm{E}^{-6}$ & 5.2 & $4.71 \mathrm{E}^{-6}$ & $5.99 \mathrm{E}^{-6}$ & $7.04 \mathrm{E}^{-6}$ & 7.39 & $9.40 \mathrm{E}^{-6}$ & $9.64 \mathrm{E}^{-6}$ \\
\hline E & $9.54 \mathrm{E}^{-7}$ & $9.98 \mathrm{E}^{-7}$ & $3.64 \mathrm{E}^{-6}$ & $8.76 \mathrm{E}^{-6}$ & $4.29 \mathrm{E}^{-6}$ & $6.35 \mathrm{E}^{-6}$ & $5.79 \mathrm{E}^{-6}$ & $7.10 \mathrm{E}^{-6}$ & $7.68 \mathrm{E}^{-6}$ & $8.14 \mathrm{E}^{-6}$ & $9.93 \mathrm{E}^{-6}$ & $1.62 \mathrm{E}^{-5}$ \\
\hline
\end{tabular}

Figure 1 (Sample C, D, and E) shows acquired magnetic moments under external magnetic fields and explicit ' $\mathrm{S}$ ' curve, which shows the positive feedback from composite material to applied magnetic field by the presence of iron (III) oxide. This magnetic moment acquisition is the result of in-built magnetic domains from iron (III) oxide particles and gives maximum magnetic moments.

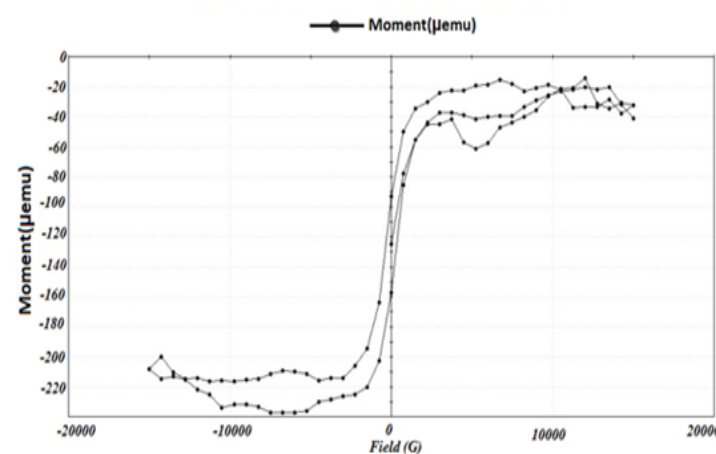

\begin{tabular}{|c|c|c|}
\hline Acquisition Mode : Point by Point & Coercivity (Hci): $0 G$ & Magnetization (Ms) : 237.44E-6e \\
\hline Mass : $25.000 \mathrm{E}-3 \mathrm{~g}$ & Maximum Field : $15000 \mathrm{G}$ & Mr, Negative: -157.38E-6 emu \\
\hline Mr, Positive : -92.918E-6 emu & Ms, Negative: -237.44E-6 emu & Ms, Positive : $-14.425 \mathrm{E}-6 \mathrm{emu}$ \\
\hline lumber of Points: 101 & Retentivity (Mr) : $32.232 \mathrm{E}-6 \mathrm{emu}$ & Sensitivity: - $-43.000 \mathrm{E}-3 \mathrm{emu}$ \\
\hline
\end{tabular}

Sample C

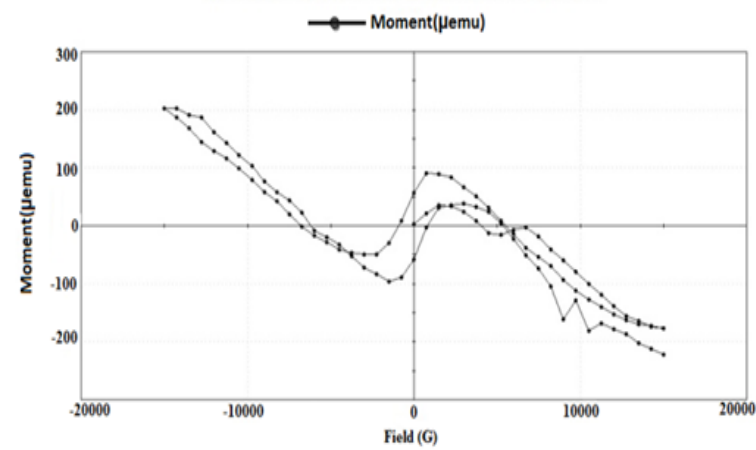

Acquisition Mode : Point by Point

Average Time: $5 \mathrm{sec}$

Coercivity (Hci): $3228.4 \mathrm{G}$

Magnetization (Ms) : $212.61 \mathrm{E}-6 \mathrm{emu}$

Mass : $26.310 \mathrm{E}-3 \mathrm{~g}$

Maximum Field: $15000 \mathrm{G}$

Mr, Negative: $-58.567 \mathrm{E}-6 \mathrm{emu}$

Mr, Positive: 57.095E-6 emu

Ms, Negative : $-222.36 \mathrm{E}-6 \mathrm{emu}$

Ms, Positive : $202.86 \mathrm{E}-6$ emu

Number of Points: 101

Retentivity (Mr): $57.831 \mathrm{E}-6 \mathrm{emu}$

Sensitivity: $-4.1000 \mathrm{emu}$

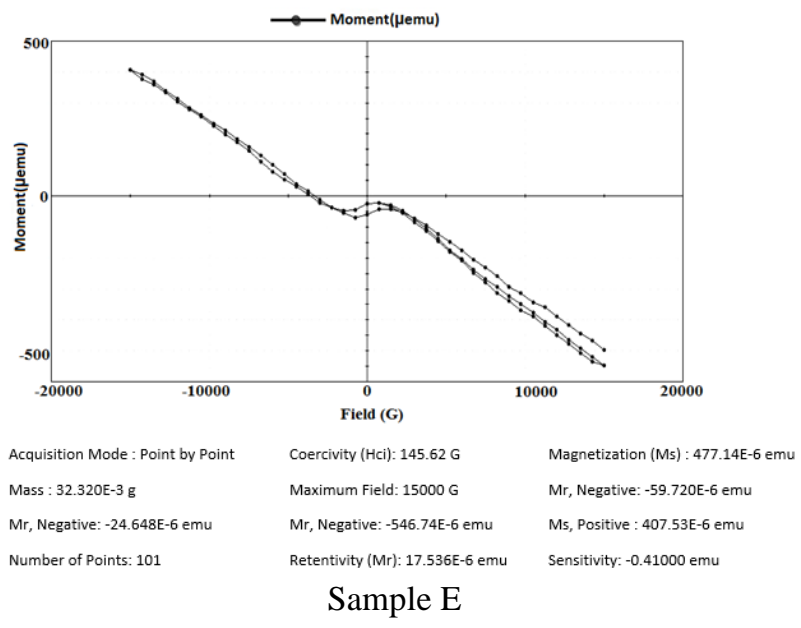

Figure 1. Hysteresis graphs of composites at $200{ }^{\circ} \mathrm{C}$

\subsection{EMI shielding}

Microwave shielding behaviour of epoxy resin composites were measured using typical microwave test bench having operating frequencies E-band (2-3 GHz), F-band (3-4 GHz), Iband (8-12 GHZ), and J-band (10-20 GHZ). The attenuation in the microwave frequency was measured using a VSWR meter in terms of output voltage.The VSWR meter was used to measure the degree of attenuation in terms of $\mathrm{dB}$ in test sample.

An incoming wave on a typical ribbon-shaped obstacle can be reflected, transmitted or absorbed. The absorption index is shown in Figure 2.

hybrid composite

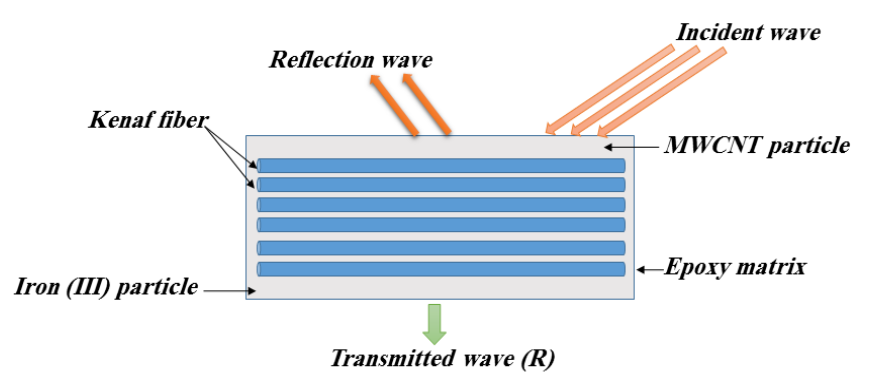

Figure 2. Smart structure proposed 


$$
A=1-R-T
$$

where, $\mathrm{R}$ and $\mathrm{T}$ are the reflected and transmitted power respectively, calculated based on the $\mathrm{S}$ parameters obtained from the vector network analyzer as follows

$$
\begin{gathered}
R=\left|S_{11}\right|^{2}=\left|S_{22}\right|^{2} \\
T=\left|S_{12}\right|^{2}=\left|S_{21}\right|^{2} \\
S_{11}=S_{22}=\frac{\Gamma\left(1-T^{2}\right)}{1-\Gamma^{2} T^{2}} \\
S_{21}=S_{12}=\frac{T\left(1-\Gamma^{2}\right)}{1-\Gamma^{2} T^{2}}
\end{gathered}
$$

where, $|\mathrm{Sij}|^{2}$ represents the power reflection $(\mathrm{i}=\mathrm{j})$ and transmission $(i \neq j)$ from port $i$ to port $j$.

As known the electromagnetic wave EM progress in the interface between metal and the air gets the same impedance, it propagates deeper into the ribbon.

\section{RESULTS AND DISCUSSION}

\subsection{Structural analysis}

In Figure 3, the graph (Figure 3a) shows the observed peaks of pure silane. The peak of $3432 \mathrm{~cm}^{-1}$ appears the existence of amine group $\left(\mathrm{NH}_{2}\right) \mathrm{N}-\mathrm{H}$ stretch in pure silane, which is also present in fibre and particle surface (Figure 3b). The peak 2900 $\mathrm{cm}^{-1}$ appears $\mathrm{C}-\mathrm{H}$ stretch, which is an attached propyle group on nano particle surface. The peak $1490 \mathrm{~cm}^{-1}$ appears the C-H bend which is in propyle group. Peak $998 \mathrm{~cm}^{-1}$ reveals the presence of condensed $\mathrm{Si}-\mathrm{O}-\mathrm{Si}$ structure on nano fibre and particle surface. The peak $828 \mathrm{~cm}^{-1}$ indicates the presence of $\mathrm{Si}-\mathrm{OCH}_{3}$ structure in pure silane (Figure $3 \mathrm{a}$ ), this is because of $\mathrm{CH}_{3}$ leaving group from silane and formation of $\mathrm{CH}_{3} \mathrm{OH}$. Thus the FT-IR spectra analysis revealed that surface modification process created $\mathrm{NH}_{2}$ functional group on iron (III) oxide surface it may improve the adhesion and even dispersion of fillers in epoxy matrix.

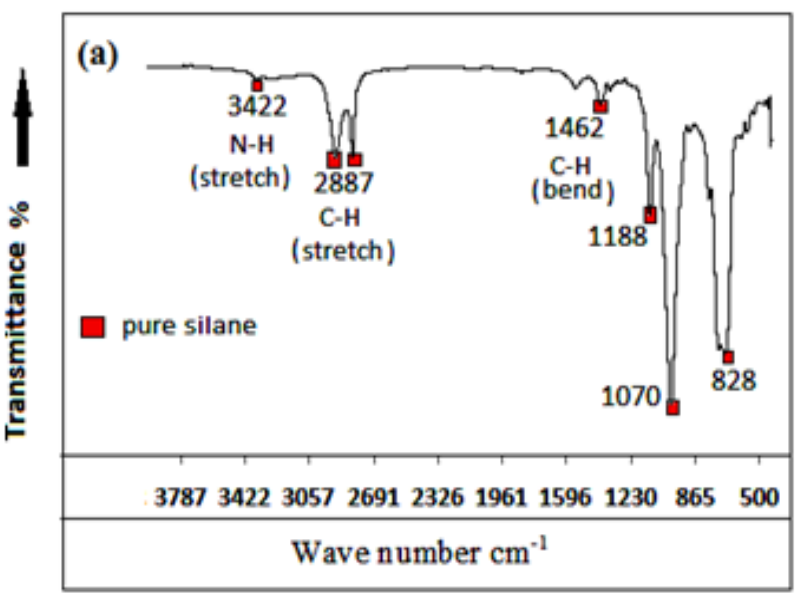

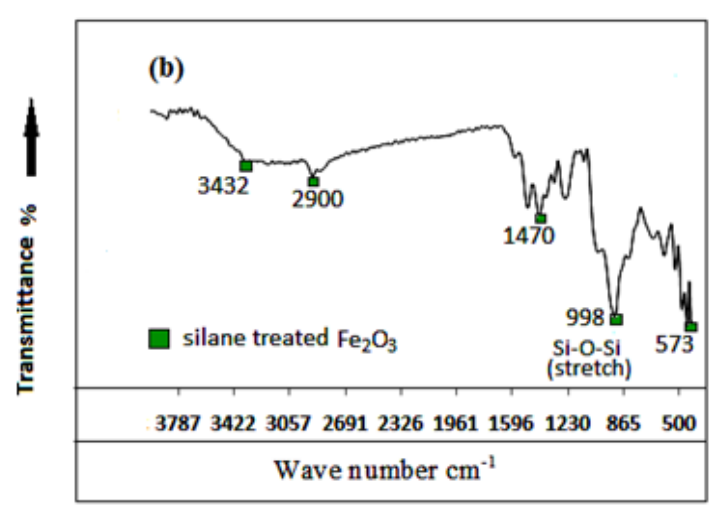

Figure 3. FT-IR Spectrum of (a) pure silane and (b) surfacetreated fibre/iron (III) oxide particle

\subsection{Reflection, absorption and SE behavior our composite in near field used in as-received condition}

Our samples are tested to understand better the effects of the frequency on the reflection, absorption losses, and EMI SE. The SE of ribbon depends on electrical conductivity, permittivity, and magnetic permeability due their impacts on $\mathrm{A}$, and $\mathrm{R}$, which were estimated using (7)-(8).

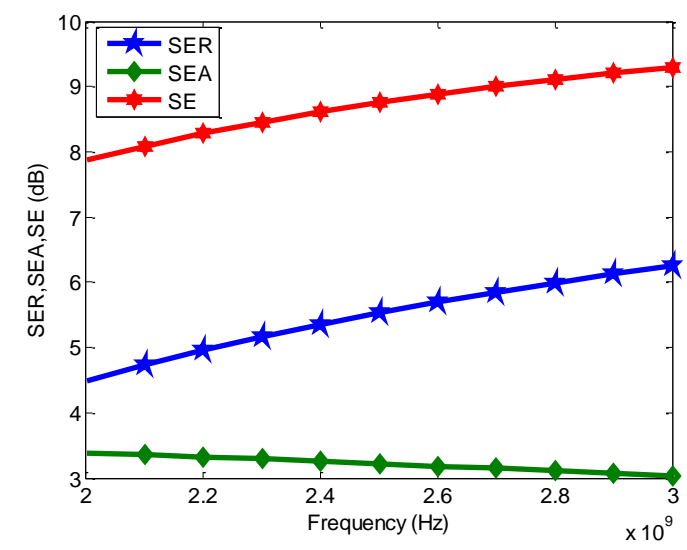

Note: SER, SEA, and SE represent the reflection loss, absorption loss, and shielding effectiveness respectively; the same as below.

Figure 4. Reflection loss, absorption loss, and SE behavior composite (Sample E) at 'E' band frequency

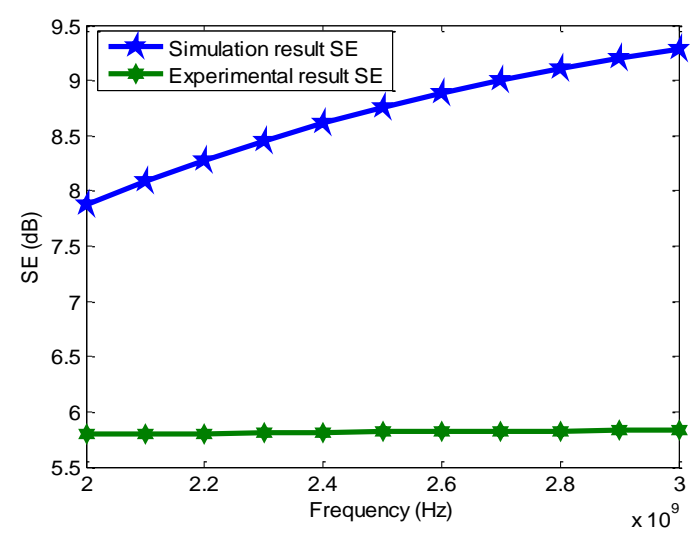

Figure 5. Comparison between experimental and simulation results of SE behavior composite (Sample E) at 'E' band frequency 


\section{A. In 'E' band (2-3 GHz)}

Figure 4 exhibits reflection loss SER, absorption loss SEA, and the total EMI SE behavior composite for sample $\mathrm{E}$ in ' $\mathrm{E}$ band frequency. Skin depth increases when the both electrical conductivity and magnetic permeability decrease. our results by designation of the proposed hybrid composite is found superior compared to the other works when utilized metallic materials by several authors because provide one of the best matter with high mechanical properties like as flexural, tensile and effects properties of bare epoxy resin matrix. However, in our case we obtained the enhancement in SE by using Iron(III), MWCNT particle addition increase the electrical properties (increase both in reflection and absorption mechanism) with an improved mechanical properties due to the multiscale reinforcement like as used kenaf fibre along dielectric epoxy matrix. The EMI SE performances of these hybrids composite were evaluated by simulation results are in good agreement with our experimental study and all the proposed composites as well shown in Figure 5, and it's had the great advantages of being low cost, mechanical strength, and light weight.

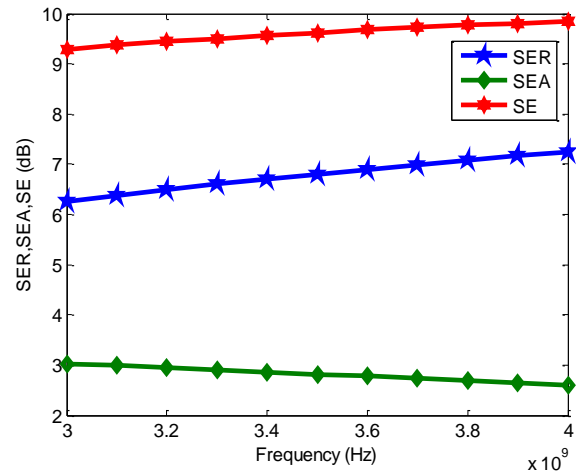

Figure 6. Reflection loss, absorption loss, and SE behavior composite (Sample E) at 'F' band frequency

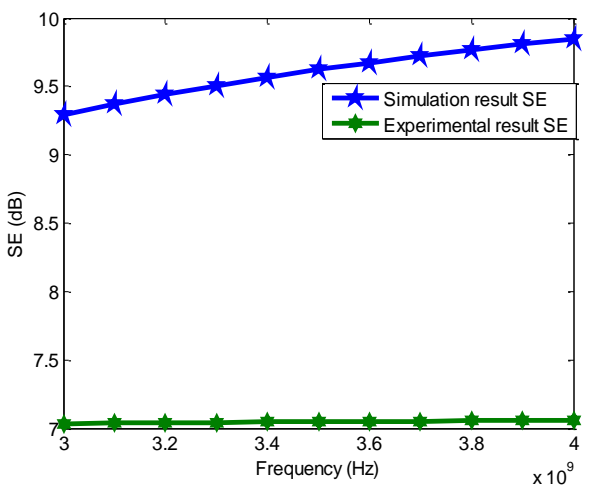

Figure 7. Comparison between experimental and simulation results of SE behavior composite (Sample E) at 'F' band frequency

\section{B. In 'F' band (3-4 GHz)}

Figure 6 exhibits the simulation results of reflection loss, absorption loss, and the total EMI SE behavior of composite sample in the E field at ' $F$ ' frequency band. These results revealed that EMI absorption mechanism increases slightly whereas EMI reflection shows a rapid enhancement. The improved reflection and absorption could be explained in terms of lowering of skin depth with the rise in both conductivity and permeability due to presence of MWCNTs, iron (III) particles addition. In other words, the results display that enhancement of absorption mechanism by an increases of skin depth, when provide a good confound between simulation and experimental work as well shown in Figure 7.

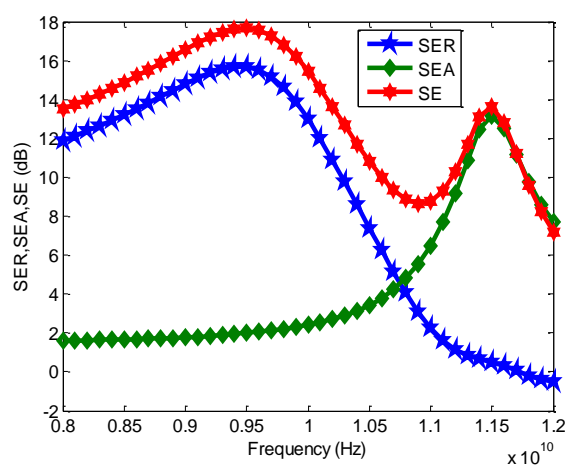

Figure 8. Reflection loss, absorption loss, and SE behavior composite (Sample E) at 'I' band frequency

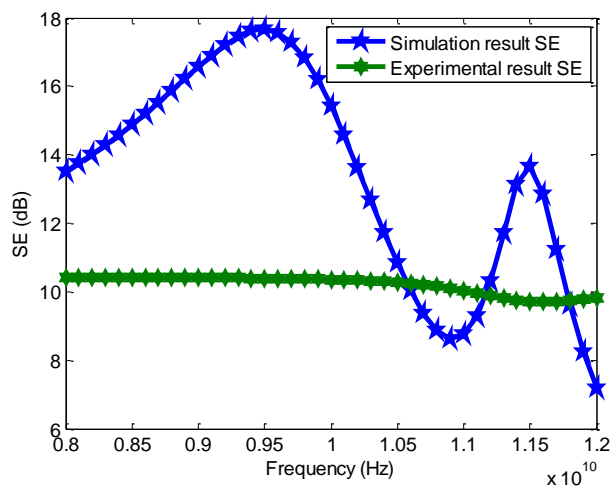

Figure 9. Comparison between experimental and simulation results of SE behavior composite (Sample E) at 'I' band frequency

\section{In 'I' band (8-12 $\mathrm{GHz})$}

Figure 8 displays the simulation results of reflection loss, absorption loss, and the total EMI SE behavior of the proposed hybrid composite for sample E at 'I' frequency band. In summary, MWCNT and iron particles addition proved to be a succeful reinforcement in matrix for producing lightweight, and high strength composites and an efficient EMI shielding material. The EMI shielding effectiveness is found to be enhanced value explained the potential of these materials as promising futuristic microwave shielding materials, by provide demonstrate in Figure 9 of our theoretical and experimental results.

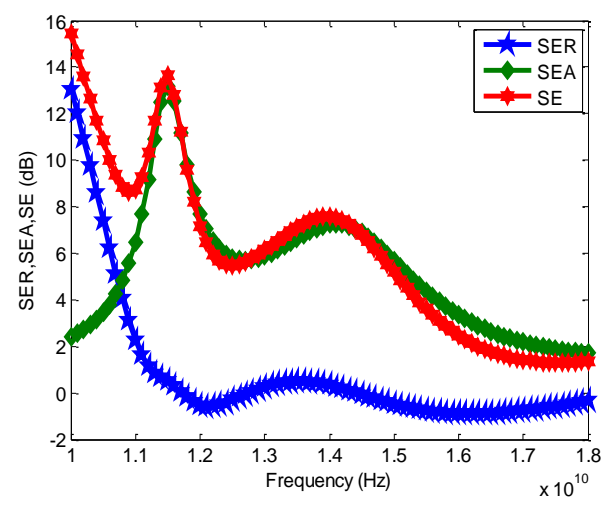

Figure 10. Reflection loss, absorption loss, and SE behavior composite (Sample E) at 'J' band frequency 


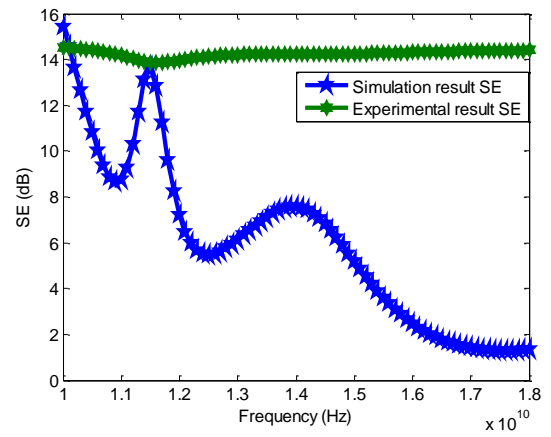

Figure 11. Comparison between experimental and simulation results of SE behavior composite (Sample E) at 'J' band frequency

\section{In 'J' band (10-18 GHz)}

The simulation results of reflection loss, absorption loss, and the total EMI SE behavior of the proposed hybrid composite for sample $\mathrm{E}$ at ' $\mathrm{J}$ ' frequency band are shown in Figure 10. The electrical conductivity of our proposed composite is sufficient to provide valid EMI SE in many applications. In addition, the surface treatment was carried out to develop the electrical proprieties between the hybrid composite to avert electromagnetic leaks as well as provide a high level of efficiency especially in military application. Thus, can be say the high level of shielding by absorption can be obtianed due their advantages of Iron (III) particle addition. We found an adequate and a good agremment results of shielding effectiveness in our proposed hybrid composite when we compared the experimental by the simulation results as show in Figure 11 for sample E at ' $\mathrm{J}$ ' frequency band.

\subsection{SE behavior our composite in near field used in surface modified condition in ' $\mathrm{J}$ ' band}

Figure 12 (a)-(b)-(c)-(d)-(e)-(f) presents a good agreement in the comparison study between experimental and simulation results under the effect of temperature on SE mechanism at $\mathrm{RT}, 100{ }^{\circ} \mathrm{C}$ and $200{ }^{\circ} \mathrm{C}$ respectively. The EMI $\mathrm{SE}$ increase with incremental electrical proprieties as conductivity, permeability, and permittivity. The relative permittivity and retentivity of composites offer a higher estimated (due their appearance of dipole Iron (III) and MWCNTs particles addition in epoxy resin matrix) and display minimum evaluation at incremental in frequency (due their small dielectric relaxation time). In addition, We noted that the hybrid composite for ' $E$ ' sample gives significant enhancement result than the epoxy resin composite at the same range of frequency due their effective particle dispersion presents by Iron (III) and MWCNTs through epoxy matrix. Moreover, we marked that in Silane surface modified composite designations gives better magnetization impact than as-received particles dispersed epoxy hybrid composite. This improvement can be explained by the addition of particle, particles dispersion and impact stability of the proposed composite under external leak field. Our hybrid composite provides the best one prepared samples when the temperature increase with the frequency. The increase of electrical conductivity due to the increase of kenaf Fibre reinforced MWCNTs and Iron (III) modified epoxy resin matrix and becomes more soft material with the temperature is the cause of increase the chances of particle network formation and decrease in resistivity.
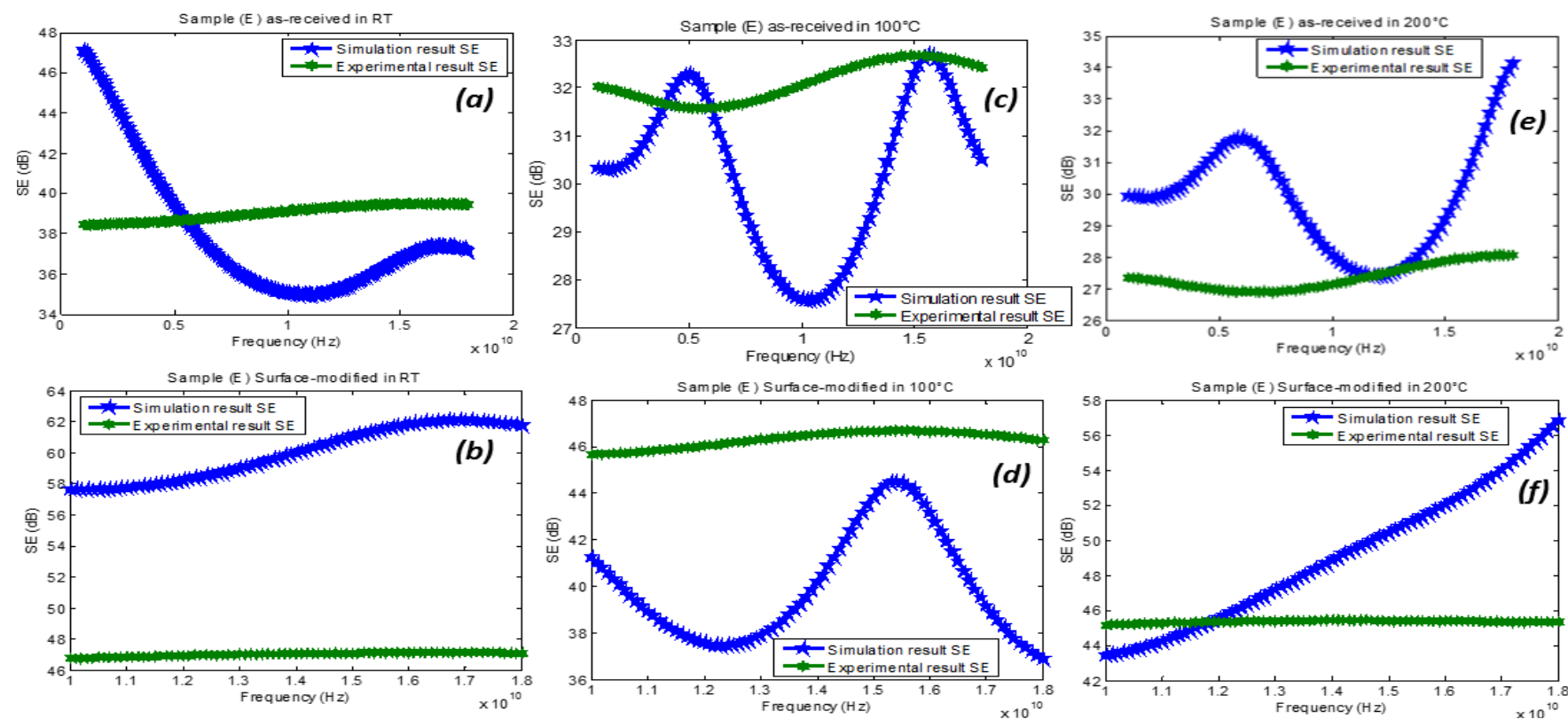

Figure 12. Comparison between experimental and simulation results of SE behavior in near field modified condition in ' $\mathrm{J}$ ' band (Sample E)

\section{CONCLUSIONS}

In this work, we have prepared a novel hybrid composite which has a good technique for commercially viable for different applications with high temperature and this method can reduce the cost of composite shields. Our composites were fabricated by using silane surface-modified MWCNTs and iron (III) nano particles addition along epoxy matrix/Kenaf fibre. Thus, its gives a larger conductivity, permeability, and permittivity than as-received reinforcements in epoxy resin at 
high temperature $200{ }^{\circ} \mathrm{C}$. The measured and simulated parameters confirm the validity of theoretical electromagnetic model with good agreement.

\section{REFERENCES}

[1] Tahar, M., Abdechafik, H., Mecheri, K. (2018). Modelling and measurement of electromagnetic shielding effectiveness. In: 2018 International Conference on Electrical Sciences and Technologies in Maghreb (CISTEM). IEEE, 2018. pp. 1-6. https://doi.org/10.1109/CISTEM.2018.8613459

[2] Merizgui, T., Hadjadj, A., Kious, M., Gaoui, B. (2019). Effect of human body temperature on new multilayer composite shield in pacemaker. Revue des Composites et des Materiaux Avances, 29(1): 27-32. https://doi.org/10.18280/rcma.290105

[3] Shen, B., Zhai, W., Tao, M., Ling, J., Zheng, W. (2013). Lightweight, multifunctional polyetherimide/graphene@ $\mathrm{Fe}_{3} \mathrm{O}_{4}$ composite foams for shielding of electromagnetic pollution. ACS Applied Materials \& Interfaces, 5(21): 11383-11391. https://doi.org/10.1021/am4036527

[4] Shen, B., Li, Y., Zhai, W., Zheng, W. (2016). Compressible graphene-coated polymer foams with ultralow density for adjustable electromagnetic interference (EMI) shielding. ACS Applied Materials \& Interfaces, $\quad 8(12)$ : 8050-8057. https://doi.org/10.1021/acsami.5b11715

[5] Merizgui, T., Hadjadj, A., Kious, M., VR, A.P., Gaoui, B. (2018). Effect of magnetic iron (III) oxide particle addition with MWCNTs in kenaf fibre-reinforced epoxy composite shielding material in ' $E$ ', ' $F$ ', 'I'and ' $J$ 'band microwave frequencies. Materials Research Express, 2018. https://doi.org/10.1088/2053-1591/aaf9de

[6] Merizgui, T., Hadjadj, A., Gaoui, B., Kious, M. (2018). Effect of temperature on the electromagnetic characteristic behavior of copper. In: 2018 International Conference on Applied Smart Systems (ICASS). IEEE, 2018. pp.

$1-5$. https://doi.org/10.1109/ICASS.2018.8652063

[7] Singh, B.P., Choudhary, V., Saini, P., Pande, S., Singh, V.N., Mathur, R.B. (2013). Enhanced microwave shielding and mechanical properties of high loading MWCNT-epoxy composites. Journal of Nanoparticle Research, 15(4): 1554. https://doi.org/10.1007/s11051013-1554-0

[8] Belaabed, B., Wojkiewicz, J.L., Lamouri, S., El Kamchi, N., Lasri, T. (2012). Synthesis and characterization of hybrid conducting composites based on polyaniline/magnetite fillers with improved microwave absorption properties. Journal of Alloys and Compounds, 527: 137-144. https://doi.org/10.1016/j.jallcom.2012.02.179

[9] Kuzhir, P., Paddubskaya, A., Plyushch, A., Volynets, N., Maksimenko, S., Macutkevic, J., Celzard, A. (2013). Epoxy composites filled with high surface area-carbon fillers: Optimization of electromagnetic shielding, electrical, mechanical, and thermal properties. Journal of Applied Physics, 114(16): 164304. https://doi.org/10.1063/1.4826529

[10] Al-Ghamdi, A.A., Al-Hartomy, O.A., Al-Solamy, F., AlGhamdi, A.A., El-Tantawy, F. (2013). Electromagnetic wave shielding and microwave absorbing properties of hybrid epoxy resin/foliated graphite nanocomposites. Journal of Applied Polymer Science, 127(3): 2227-2234. https://doi.org/10.1002/app.37904

[11] Cao, M.S., Yang, J., Song, W.L., Zhang, D.Q., Wen, B., Jin, H.B., Yuan, J. (2012). Ferroferric oxide/multiwalled carbon nanotube vs polyaniline/ferroferric oxide/multiwalled carbon nanotube multiheterostructures for highly effective microwave absorption. ACS Applied Materials \& Interfaces, 4(12): 6949-6956. https://doi.org/10.1021/am3021069

[12] Merizgui, T., Hadjadj, A., Gaoui, B., Kious, M. (2018). Comparison electromagnetic shielding effectiveness between smart multilayer arrangement shields. In: 2018 International Conference on Applied Smart Systems (ICASS). IEEE, 2018. pp. 1-5. https://doi.org/10.1109/ICASS.2018.8651965

\section{NOMENCLATURE}

$\begin{array}{ll}\text { EMI } & \text { Electromqgnetic interference } \\ \text { SE } & \text { Shielding effectiveness } \\ \text { PMC } & \text { Polymer composite }\end{array}$

\section{Greek symbols}

$\sigma \quad$ Electrical conductivity

$\mu \quad$ Magnetic permeability

$\varepsilon \quad$ Electrical permittivity

\section{Subscripts}

$\mathrm{T} \quad$ temperature

CNT Carbon nano-tube

NC Nanocomposite 